\title{
Implementation Method of Master Slave System for Motorcycle and Safety Helmets
}

\author{
Nova Suryangga \\ Electrical Engineering \\ University Merdeka Of Malang \\ Malang Indonesia \\ Suryangga.nova@gmail.com
}

\begin{abstract}
Motorcycle theft often occurs due to many factors other than the theft of a motorcycle helmet is now rampant theft occurs, in this study the authors focus the security both of these by using the communication system master slave on a bike motorcycle and helmet so it can trigger an alarm when a helmet or motorcycles stolen and for additional security features were added to the tracking using the GPS module and GPS tracker bravo so give extra safeguards on the motorcycle and helmet.
\end{abstract}

Keywords- Master slave; GPS; The alarm; Motorcycles; Helmet.

\section{INTRODUCTION}

RFID is a technology that uses communication via electromagnetic waves to Exchange data that is usually applied to livestock, goods and human beings for the purpose of identification through the use of devices called RFID tags. RFID tags can be active or passive. Passive RFID tags do not have their own power supply [1], so the price is cheaper than active tags. Wireless anti lost alarm distance is a technology shaped the electronic module which is useful to detect the distance between the device master with slave devices [2] who will react to the sound of the buzzer when the distance both being out of range. GPS tracker tags is a handy electronic modules give the position to the receiver or server under certain conditions [3], this tool is very useful to detect or anticipate losing stuff and easily applied because of its small size.

By using the modules then the writers will draw up a device that can secure motorcycle and helmet, the way it works is the RFID enabled additional safety as a key motor in addition to the key contacts, RFID only served as switch stand-by or off alarm or security system for the motor. Wireless anti lost alarm distance is used to identify the distance between the helmet and motorcycle, motorcycle Horn will beep when the helmet is beyond wireless anti lost alarm distance, while at the helm the buzzer will sound. GPS tracker tags will be used when the helmet was stolen and the distance is very far from the motor, with the module owner of the helmet can track the position of the helmet using the tracker on a smartphone.

\section{Methodology}

\section{A. Research Variables}

In the design and manufacture of tools there are variables to be tested. To know the quality of the design of the tool then in this research there are three variables that will be researched and analyzed in hopes of knowing how far the system the tool is running.

\section{B. The functionality of the device}

Test the functionality in order to find out if all the functionality of an electronic device can be terintegerasi and it works well.

1) Reaction Range Wireless Anti Lost Alarm and Distance GPS trackert.

2) The distance reading of RFID.

\section{Parameter}

The parameters used in testing aimed at knowing the quality of the design that will be researched and analyzed in hopes of knowing how far the system is running the tool.

1) The distance

Distance as a parameter on the research of this final project is aiming to do the test at the time closer to RFID tags user triggers certain actions on the system, the maximum distance from wireless anti lost alarm and GPS tracker response.

\section{The Model Architecture Scheme}

This tool provides security on a motorcycle and helmet to help two-wheeled motor vehicle owners in securing the vehicle. Flow performance of the tool are as follows:

1) Wireless anti lost alarm distance is in charge of identifying the distance a helmet to the motor and rang the buzzer when the helmet is out of reach.

2) RFID serves as additional default key key motor bike, and function enable and disable the alarm.

3) Nano Arduino Microcontroller is used for reading the input from each of the modules.

4) Motorcycle Horn is used as an alarm output. 




Fig. 1. Module Placement chart On Helmets and Motorcycle

In Figure 1 explained that the inputs are first read by RFID and sensor systems are the key contacts of the motor, the input should be given so that the alarm can serve is the key contact RFID scanner and read off the value of a card or RFID tags. While so that the alarm can be turned off with the correct input which is expected to equal the time of alarm triggers but the key contact in the conditions on. Safety helmet for the initial conditions that expected that the alarm function is helm detected by proximity sensor and RFID scanner to read the value of a card or RFID tags for menonaktifakan alarm input should be given a helmet is a helmet not detected by proximity sensor or have been taken and the RFID scanner reads the value of the tag and for the output is

1) RFID detected True and contacts $\mathrm{ON}=$ motor can be started.

2) RFID detected False and contacts $\mathrm{ON}=$ motor cannot be started and the alarm goes off and send an SMS notification to smartphone owners.

3) RFID detected True and helmets taken $=$ alarm goes off no helmet.

4) RFID detected False and Helmets taken $=$ alarm motor and the helmet reads, as well as sending an SMS notification to smartphone owners in the form of GPS positions of the helmet.

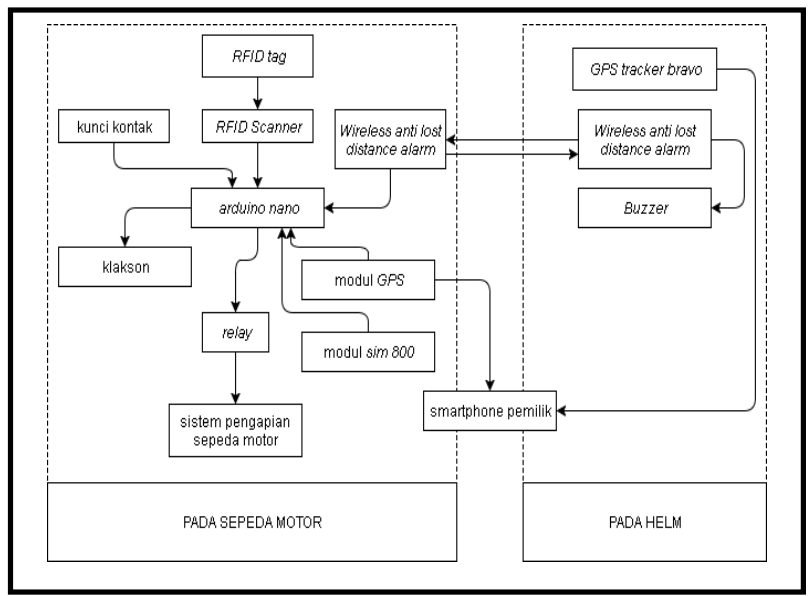

Fig. 2. Block Diagram
The most important thing to look for in making the design of something that is a block diagram of the mencankup workings of the tool which is designed, then the characteristics of the components used, the overall block diagram of the implementation of RFID, Wireless anti lost distance alarm and GPS tracker as a motorcycle and safety helmets using the arduino microcontroller nano and in Figure 2 is an overview and explanation of the structure of the block diagram of the final project.

In Figure 2 is a block diagram that describes the work system of tools used in research and development at this final task is RFID, Wireless anti lost alarm and distance GPS tracker, for kalkson and relay output is in charge disconnect the current from the battery to the ignition system, motorcycle GPS data sent from a GPS tracker which is put on the helmet, the buzzer goes off in his helmet. The workings of a device installed in motor bikes is reading data from the RFID tags as the initialization to turn off or turn on the alarm that will be processed by an arduino, arduino functions is as the main controller of work each module connected to it, the SIM module 800 used to send sms GPS coordinates when it happens the theft marked with the position of the ignition On but the alarm is still active. Ublox GPS module is used to get the GPS coordinates will be sent using SMS to detect the presence of the helmet using a communication master slave from Wireless Anti Lost Alarm Distance found on motorcycles and helmets. At the helm there is Tracker Bravo used to take GPS coordinates when stolen helmet.

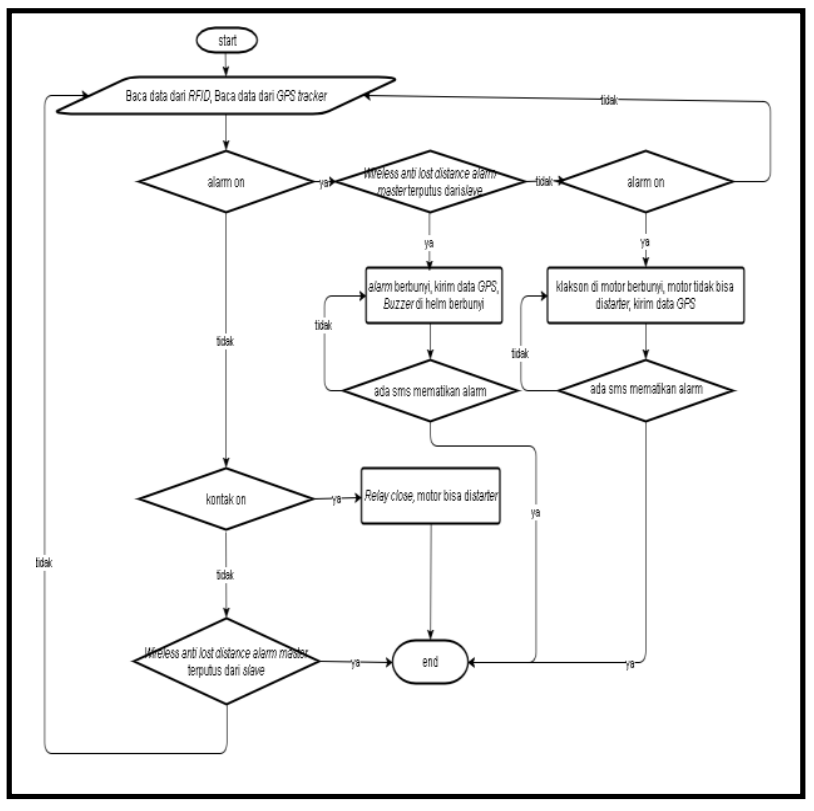

Fig. 3. Flowchart

In figure 3. if detected Alarm value from RFID scanner that indicate alarm conditions active then if the helmet is taken to mean the Horn will beep as well if the condition of the ignition is active but also the alarm is active, to turn off the alarm so that the Horn is not reads are the same time turn it on. If the alarm is turned off earlier by the owner indicates that the helmet is taken by the owner or the owner's actually valid while if scanner does not accept data and helmets taken then indicated as acts of theft as well as to alarm If the motorcycle 
ignition on but the scanner does not accept value then indicated occurred theft.

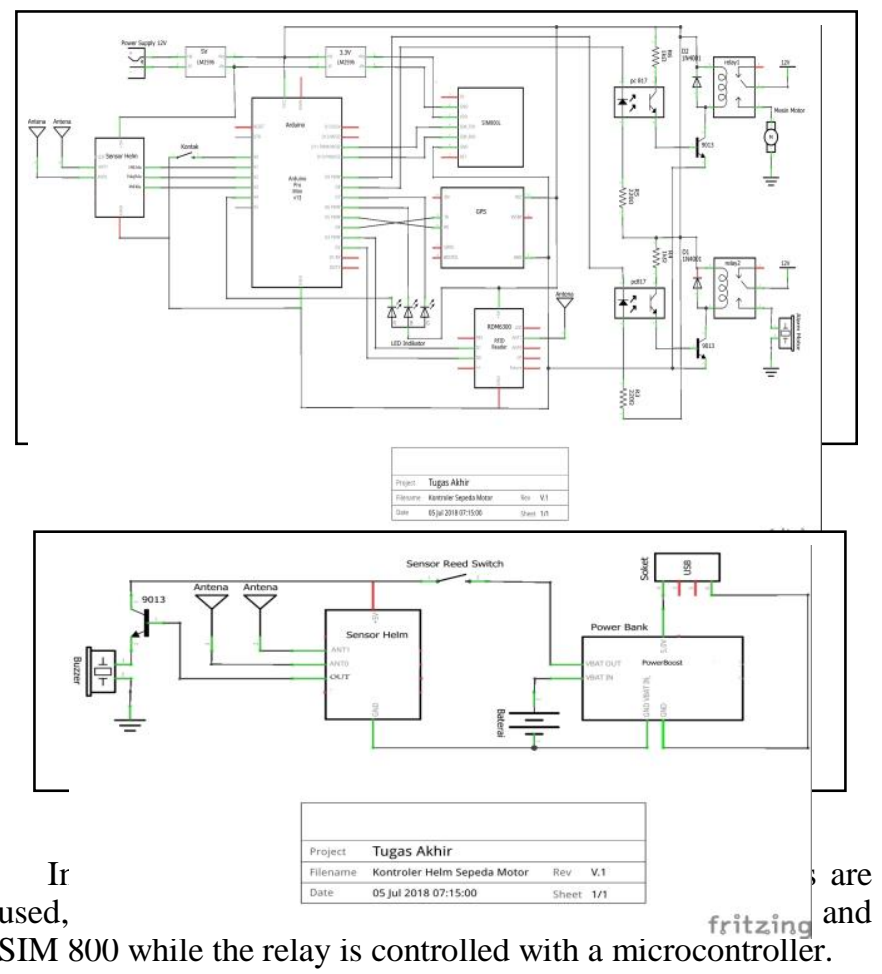

In Figure 5. explained how each device that is mounted on the helmet, the communication master slave applied so that between motorcycle helmet and connected when this connection is disconnected will trigger the buzzer. Reed switch sensor is used as a switch that can turn on and turn off the master slave communication between helmet and motorcycle while the power supply is obtained from powerbank of $3 \mathrm{v}$.

\section{RESULT AND ANALYSIS}

The result of designing tools applied in motorcycles and helmets is the design of modules mounted on the motorcycle and the design of modules mounted on the helmet. From the results of the design that has been completed then it can be done testing procedures to be applied.

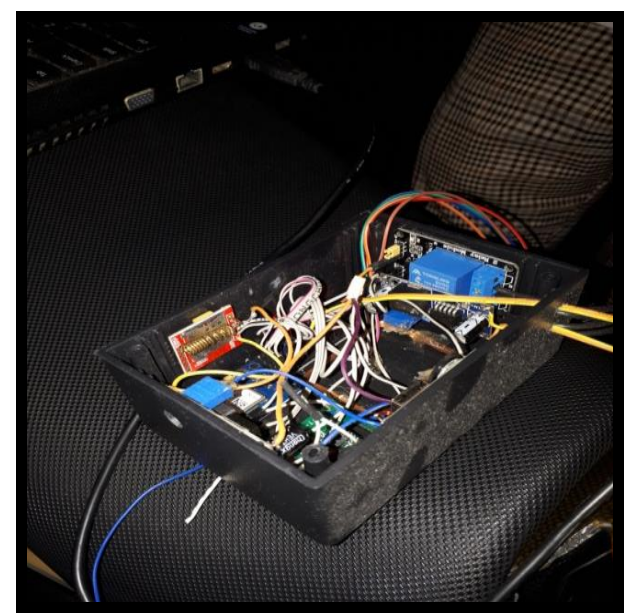

Fig. 6. The module is mounted on a motor bike

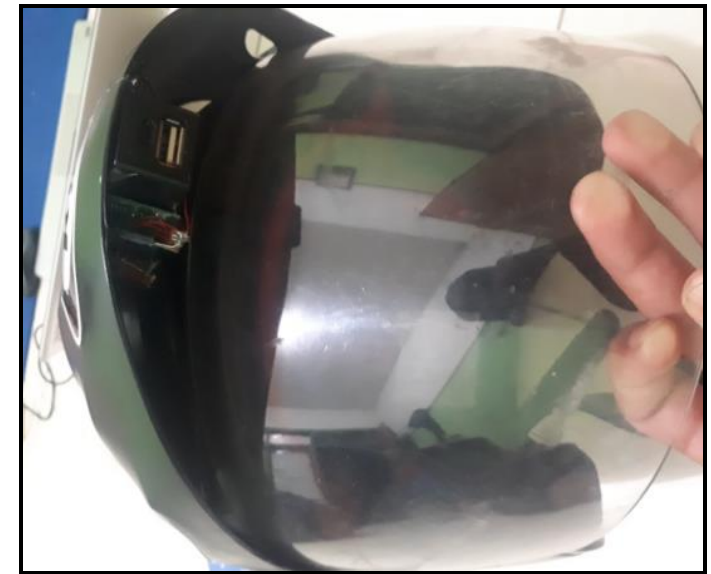

Fig. 7. Device mounted on a helmet

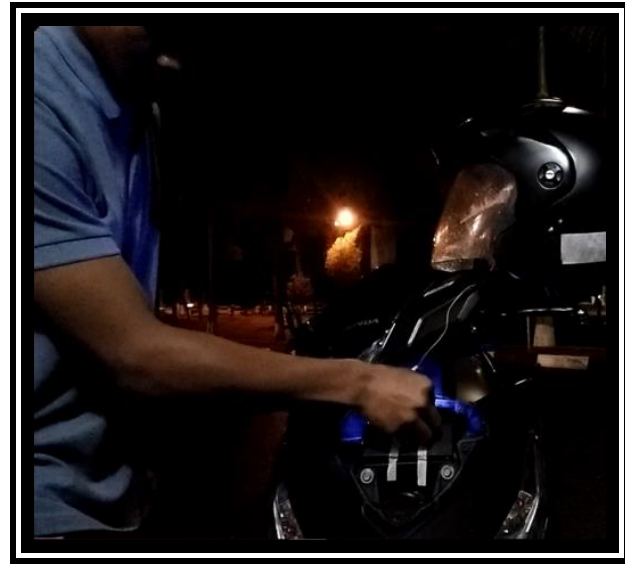

Fig. 8. Testing RFID Module

In Figure 6. is the application of the design tools are mounted on a motorcycle, in this section there is an Arduino microcontroller function control and read data from the GPS module, Wireless Anti Lost Alarm and RFID. The Arduino will read data from a serial GPS and RFID modules, while for Wireless Anti Lost Alarm will be read using the ADC. The series itself is a data communication method used in electronics devices and useful mentranmisikan data between the device and the other one, while ADC Analog to Digital Conversion is a method that convert the output analog of a device into a digital form in order to be processed by a microcontroller.

In this section there are some devices that are merged into one between the other GPS Tracker Bravo, Buzzer, Alarm and Wireless Anti Lost reed switch switches to turn off and turn on the alarm, the way it works is if the helmet is lost then the owner can track them with GPS Tracker with Tracker application Bravo Bravo Android Play in Store, while the task of Wireless Anti Alaram Lost to identify distance helmet and motorcycle with helmet and will trigger the alarm on a motorcycle and helmet When the helmet is outside the range of the Wireless communication Anti Lost Alarm.

In Figure 8. shows the alarm activation process by using RFID tags. Alarm indicator has been active is marked with red color LED lights up alternating with blue LEDS. Table 4.1. shows the results of testing the devices mounted on the 
motorcycle with testing as much as five times the IE testing on the top, bottom, right side, left side, front on RFID module.

TABLE I. TESTING OF RFID

\begin{tabular}{|c|l|}
\hline distance & \multicolumn{1}{|c|}{ status } \\
\hline $1 \mathrm{~cm}$ & can read and can turn on or turn off the alarm. \\
\hline $2 \mathrm{~cm}$ & can read and can turn on or turn off the alarm. \\
\hline $3 \mathrm{~cm}$ & can read and can turn on or turn off the alarm. \\
\hline $4 \mathrm{~cm}$ & of the reading experience a problem. \\
\hline $5 \mathrm{~cm}$ & $\begin{array}{l}\text { cannot read and cannot turn on or turn off the } \\
\text { alarm. }\end{array}$ \\
\hline
\end{tabular}

Table 1. shows the RFID module test results that indicate the distance optimal for reading RFIG tag is between one to three centimeters, at a distance of the RFID reader can read the value of the tag and can enable alarm or deadly alarm.

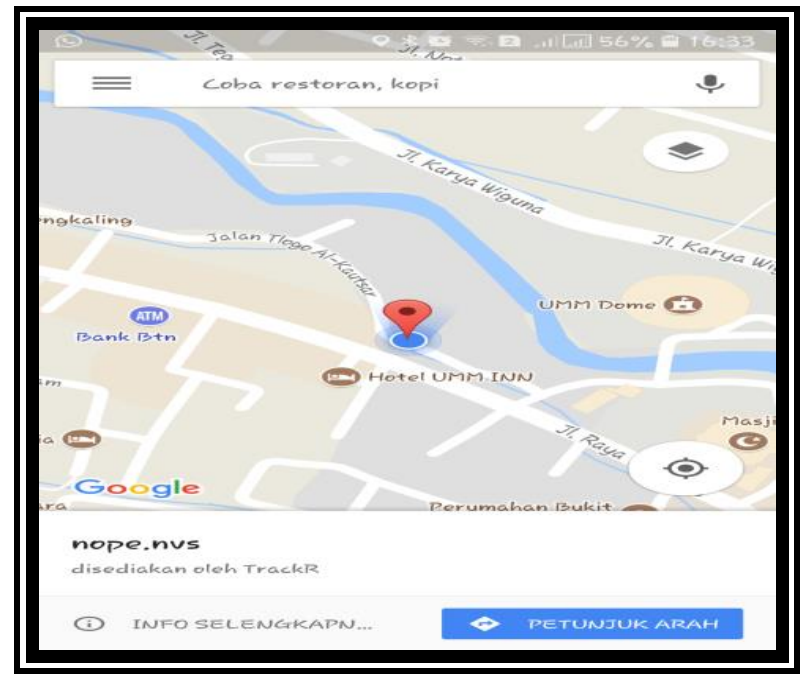

Fig. 9. Testing the GPS module

In Figure 9. shows the GPS module can work properly and shows the appropriate location on a Google Map based on the GPS coordinates, GPS coordinates sent by SMS from tools mounted on a motorcycle to motorcycle owners mobile phone. Indicators are used to identify the condition of the GPS signal is detected the LEDS light up in blue on the box that indicates the GPS data can be processed by an Arduino Microcontroller.

TABLE II. TESTING WIRELESS ANTI LOST ALARM

\begin{tabular}{|c|l|}
\hline distance & result \\
\hline 20 & alarm on a motorcycle and helmet not reads \\
\hline 30 & alarm on a motorcycle and helmet not reads \\
\hline 40 & alarm on a motorcycle and helmet not reads \\
\hline 50 & alarm on a motorcycle and helmet reads \\
\hline 60 & alarm on a motorcycle and helmet reads \\
\hline
\end{tabular}

In table 2. shows the results of testing Wireless Anti Lost Alarm indicating the Distance setting the distance at $50 \mathrm{~cm}$ will activate or trigger alarms on the helmet and motorcycle at a distance of $20 \mathrm{~cm}$ to $40 \mathrm{~cm}$ alarms not triggered because the communication master slave on this module can still connect and at a distance of $50 \mathrm{~cm}$ communication master slave is disconnected which resulted in an alarm is triggered.

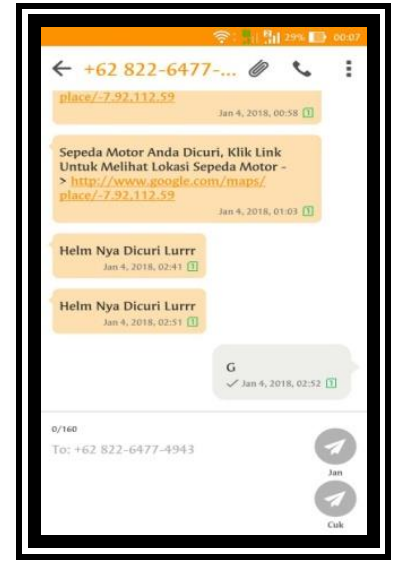

Fig. 10. The test results of the SIM Module 800

Based on the test shown in Figure 10. indicates that the SIM SMS module 800 can function properly and can send the coordinates of a motorcycle through an SMS containing the latitude and longitude. As well as the owner can turn off the alarm when the sms from the owner of the motor module SIM SMS accepted by 800 .

\section{A. Testing Device that is mounted on the helmet}

This test is done to find out the performance of the GPS Tracker module Bravo, Buzzer and modules Wireless Distance an Anti Lost Alarm. Model testing to be performed are as follows:

1) Testing the GPS module Tracker Bravo, to know the GPS module can send the coordinates of the helmet. On testing this using an application tracker available in the playstore bravo.

2) Test the buzzer, the buzzer will beep when the helmet to be away from the motorcycle so that the communication master slave is disconnected.

3) Testing modules Wireless Distance an Anti Lost Alarm to know master slave communication can work or not. And when the master slave communication was cut off, the buzzer is triggered.

Testing tools are mounted on a helmet, done with testing on each device is used. Model testing does is keep the helmet of motor bike with a certain distance, starting from a distance of $20 \mathrm{~cm}$ to $40 \mathrm{~cm}$ distance and the alarm was not triggered because the communication master slave has not been disconnected. At a distance of $50 \mathrm{~cm}$ communication master slave is disconnected and triggers an alarm on the motorcycles and helmets. The testing process takes the coordinates of GPS Tracker with Tracker application Bravo Bravo in Android generates the coordinates in the form of GPS data that is unreadable on a tracker application bravo in the Android smartphone.

Based on the test procedures have been conducted and the results obtained during testing it can be concluded that all modules have been installed to function in accordance with the design. GPS tracker bravo can work properly and send GPS coordinates. Then the module Wireless Distance an Anti Lost Alarm can communicate in master with slave modules on a 
motorcycle and can trigger the buzzer when the communication master slave is disconnected.

\section{B. The overall testing devices on Motorcycles and helmets.}

This test aims to find out the overall functionality of the system device that has been compiled in accordance with the design, scenario testing is done is as follows:

1) Testing enable the alarm with RFID.

2) Turn on the motorcycle Test without turning off the alarm.

3) Testing the GPS data send by text message every ten seconds when the motor is simulated divest victims.

4) Turn off the alarm with the RFID Testing then turned on the motorcycle.

5) Testing alarm activates at the helm.

6) Testing took the helm with a distance of motorcycles of more than $50 \mathrm{~cm}$.

7) Send SMS messages while Testing helmet simulated divest victims.

8) Testing the tracker coordinates the bravo helmet divest victims using simulated application tracker bravo.

9) Testing turn the alarm off on the motorcycle that read by sending SMS to disepeda-mounted motor.

10) Testing turn the alarm off on the motorcycle that goes with RFID. In this simulation assumed the helm returned to the place of beginning.

11) Test the alarm turn on and off with RFID. Then turn on the motorcycle.

The process of testing the whole device attached to a motorcycle and helmet. With scenario testing enable the alarm using RFID so that the alarm is active the LED marked with red color. Testing turn on the bike without turning off the alarm causes the Horn goes off on a motorcycle. Testing sending GPS data via SMS every ten minutes, when the motor is simulated stolen produce SMS received by motorcycle owners in the form of GPS coordinates are changed during the last ten minutes. Turn off the alarm with the RFID testing then turned on the motor cycle resulting in the Horn stop beeping after RFID tags are brought on the RFID reader is mounted on a motorcycle. Testing the alarm activates at the helm there alarm active helmet is marked with red LED on a motorcycle. Testing takes the helm with a distance of motorcycles of more than 50 $\mathrm{cm}$ resulting in buzzer on the helmet reads because the master slave communication between motorcycles and helmets. Send SMS messages while testing helmet simulated stolen and only once delivery of SMS alarm can be turned off.

Testing see the coordinates of the simulated stolen helmet by bravo tracker coordinates can be shown. Testing turn off the sound alarm on the motorcycle that reads as well as using SMS from the owner of the motorcycle, the Horn can stop the beeping when SMS received by the device installed on the motorcycle. Testing turn the alarm off on the motorcycle that goes with RFID, in this simulation assumed the helm returned to the original place so the Horn stop beeping when the RFID tag read by a RFID reader on motorcycles. Testing turn on and off the alarm properly and then turning on the bike produces a motorcycle can be used as normal so that it can be summed up all the testing has been completed successfully and the system works according to the the design.

\section{ACKNOWLEDGMENT}

After doing the design stage in accordance with the methods of research and manufacturing work system in accordance with the workings of the planning tools are in the testing phase and resume in can be done using a variety of models testing, then the result from the testing that has been done is as follows:

1) Testing by using a variable distance for testing RFID tags to RFID scanner are obtained optimal distance is used preferably no more than $2 \mathrm{~cm}$ as a maximum reading of RFID is $2 \mathrm{~cm}$.

2) Testing wireless anti lost alarm distance can work optimally at a distance of $40 \mathrm{~cm}$ and an alarm will be triggered if the distance is more than $40 \mathrm{~cm}$, for wireless data communication anti lost alarm cut off the distance so that it can trigger an alarm goes off.

3) Testing tracker bravo at the helm can work in accordance with its functions with the records should be connected with bluetooth and internet connection which is adjacent to module tracker bravo bravo tracker not because can stand by itself like GPS ublox.

4) Testing the Ublox GPS module on a motorcycle can work in accordance with the workings of the actual GPS with a note must be connected on the network the internet that unstable and normal so as to indicate the appropriate coordinate locations and can in tracking.

5) Work system of the Master and Slave can work in accordance with its methods of work planning tools at disposal that is able to communicate the data send and receive wireless anti lost alarm distance. By doing the testing procedures applied.

Any suggestionsFrom the results of research that has been done there is testing some parts that need to be perfected, among others, the election of the Master and Slave communications sensor that has a high sensitivity, the use of RFID can be replaced with a new device that is more sophisticated and packaging devices as well as placement can be reorganized so that it is cleaner and safer from the risk of shorting due to water or other things.

\section{REFERENCES}

[1] Alwin, Muhammad Riyan, Addy Suyatno, and Indah Fitri Astuti. "Implementasi RFID Tag Pasif Sebagai Pengaman Tambahan Pada Sepeda Motor." Jurnal Informatika Mulawarman .JIM. 7.2. 2016. 55-57.

[2] Xu, Jiuqiang, et al. "Distance measurement model based on RSSI in WSN." Wireless Sensor Network 2.08. 2016. 606.

[3] Bouten, Willem, et al. "A flexible GPS tracking system for studying bird behaviour at multiple scales." Journal of Ornithology 154.2 2015.: 571580 .

[4] Zulkifli, N. S. A., FK Che Harun, and N. S. Azahar. "XBee wireless sensor networks for Heart Rate Monitoring in sport training." Biomedical Engineering .ICoBE., 2012 International Conference on. IEEE. 2015.

[5] Ardhianto, Aan. Pemanfaatan mikrokontroler atmega8535 dan sensor pir sebagai pengendali alat pengering tangan. Kinetik. Universitas Sebelas Maret. 2016. Ardhianto, Aan. Pemanfaatan mikrokontroler atmega8535 
dan sensor pir sebagai pengendali alat pengering tangan. Kinetik. Universitas Sebelas Maret. 2016.

[6] Metzger, Christian, Matt Anderson, and Thad Starner. "Freedigiter: A contact-free device for gesture control." Wearable Computers, 2014 ISWC 2014. Eighth International Symposium on. Vol. 1. IEEE. 2014.

[7] Casebolt, Mark W., and Mark R. Lee. "Proximity sensor with adaptive threshold." Wearable Computers, 2014. ISWC 2014. Eighth International Symposium on. Vol. 1. IEEE. 2014.

[8] Zikraniko, Donni. "Rancang Bangun Mesin Penghancur Gelas Plastik Otomatis Menggunakan Atemega 8535." Kinetik. 2013 ejournal.unp.ac.id

[9] Kourogi, Masakatsu, et al. "Indoor outdoor pedestrian navigation with an embedded GPS, RFID, self-contained sensor system." Advances in Artificial Reality and Tele-Existence. SemanticScholar. Vol. 2 . 2015.

[10] Basori, Basori, Subagsono Subagsono, and Husin Bugis. "Pemanfaatan Mikrokontroller AT89S51 Dalam Rancang Bangun Ssistem Water Injection Berbasis Mikrokontroler Pada Sepeda Motor." Jurnal Ilmiah Pendidikan Teknik dan Kejuruan 7.2. 2017.

[11] [11] Blackett, Andrew W., Bryan J. Gilbert, and Martin A. Hancock. "Method and system for master slave protocol communication in an
Intelligent electronic device." ISWC 2014. Eighth International Symposium on. Vol. 1. IEEE. 2014.

[12] Riyadi, Slamet, and Bambang Eka Purnama. "Sistem Pengendalian Keamanan Pintu Rumah Berbasis SMS .Short Message Service. Menggunakan Mikrokontroler Atmega 8535." IJNS-Indonesian Journal on Networking and Security 2.4. 2015.

[13] Chamim, Anna Nur Nazilah. "Penggunaan Microcontroller Sebagai Pendeteksi Posisi dengan Menggunakan Sinyal GSM." Jurnal Informatika 4.1. 2012.

[14] Achmad, Balza, Wahyu Sapto Aji, and Wahyu Paningal. "Sistem Alarm Mobil Menggunakan Mikrokontroler AT89S52 Berbasis SMS." Jurnal Telkomnika, Program Studi Teknik Elektro, Universitas Ahmad Dahlan, Yogyakarta 6.1. 2012.

[15] Izzatika, Meilinda. Pengama Tas Menggunakkan Teknologi Global Positioning System.GPS. Dengan Sensor LDR Via Short Message Service .SMS. Sub Bahasan: Sensor LDR. Kinetik. Politeknik Negeri Sriwijaya. 2015 